УДК 796

DOI https://doi.org/10.26661/2663-5925-2021-2-08

\title{
ЗАСТОСУВАННЯ ІННОВАЦЙНИХ ЗАСОБІВ У НАВЧАЛЬНО-ТРЕНУВАЛЬНОМУ ПРОЦЕСІ В ГАНДБОЛІ
}

Тищенко В. О.

доктор наук з фізичного виховання і спорту, професор, професор кафедри теорії та методики фізичної культури і спорту

Запорізький національний університет

вул. Жуковського, 66, Запоріжжя, Украӥна

orcid.org/0000-0002-9540-9612

valeri-znu@ukr.net

Лочман В. А.

тренер чоловічої юнацької збірної U-19

Федерачія гандболу Украӥни

вул. Січових стрільців, 10, офіс 39, Київ, Украӥна

orcid.org/0000-0001-6201-4596

v.lochman2017@gmail.com

Мордвинов К. О.

аспірант кафедри теорії та методики фізичної культури і спорту

Запорізький національний університет

вул. Жуковського, 66, Запоріжжя, Украӥна

orcid.org/0000-0001-6201-4596

handball.survey@gmail.com

Бєлоус М. А.

аспірант кафедри теорії та методики фізичної культури і спорту

Запорізький національний університет

вул. Жуковського, 66, м. Запоріжжся, Україна

orcid.org/0000-0002-2495-8032

Misha_belous@ukr.net

Тищенко Д. Г.

студент магістратури

факультету фізичного виховання, здоров'я та туризму

Запорізький національний університет

вул. Жуковського, 66, м. Запоріжжя, Украӥна

orcid.org/0000-0001-6201-4596

handball.survey@gmail.com

Ключові слова: гандбол, фізична підготовка, інноваційні засоби.
Мета дослідження - здійснити аналіз застосування інноваційних засобів у навчально-тренувальному процесі в гандболі. Об'єкт дослідження навчально-тренувальний процес у гандболі. Предмет дослідження показники рівня фізичної підготовленості. Суб'єкт дослідження спортсмени команди «Академія гандболу». Методи дослідження: аналіз i узагальнення науково-методичних джерел за темою дослідження; педагогічні спостереження; педагогічний експеримент; методика 
визначення рівня фізичної підготовленості; методи математичної статистики під час оброблення результатів дослідження. Результати дослідження. Порівняльний аналіз прикінцевих даних контрольної (займалася за традиційною методикою) та експериментальної (iз використанням інноваційних засобів i технічних засобів) груп констатував достовірні зміни в чотирьох тестах із восьми: у потрійному стрибку з місця, комплексній вправі, метанні м'яча на дальність однією рукою стоячи та двома руками сидячи. Висновки. Вирішення завдання підвищення якості процесу підготовки гандболістів передбачає широке використання інноваційних інформаційних технологій у системі спортивного тренування, що вимагає систематичного вдосконалення навчально-тренувальних занять, модернізації методів спортивного тренування, використання досягнень науково-технічного прогресу та передового спортивно-педагогічного досвіду. Упровадження інноваційних та інформаційних технологій дозволяє оптимізувати процес формування, розвитку і вдосконалення фізичних якостей гандболістів. 3 їхньою допомогою не тільки підвищується емоційний фон, але i прискорюється навчання або вдосконалюються окремі навички.

\section{APPLICATION OF INNOVATIVE MEANS IN THE EDUCATIONAL PROCESS IN HANDBALL}

Tyshchenko V. O.

Doctor of Sciences in Physical Education and Sports, Professor, Professor at the Department of Theory and Methods

of Physical Culture and Sports

Zaporizhzhia National University

Zhukovskoho str., 66, Zaporizhzhia, Ukraine

orcid.org/0000-0002-9540-9612

valeri-znu@ukr.net

Lochman V. A.

Coach of the men's youth team U-19

Handball Federation of Ukraine

Sichovykh striltsiv str., 10, office 39, Kyiv, Ukraine

orcid.org/0000-0001-6201-4596

v.lochman2017@gmail.com

Mordvynov K. O.

Postgraduate Student at the Department of Theory and Methods of Physical Culture and Sports

Zaporizhzhia National University

Zhukovskoho str., 66, Zaporizhzhia, Ukraine

orcid.org/0000-0001-6201-4596

handball.survey@gmail.com

Belous M. A.

Postgraduate Student at the Department of Theory and Methods of Physical Culture and Sports

Zaporizhzhia National University

Zhukovskoho str., 66, Zaporizhzhia, Ukraine

orcid.org/0000-0002-2495-8032

Misha_belous@ukr.net 


\author{
Tyshchenko D. H. \\ Master's Degree Student \\ at the Faculty of Physical Education, Health and Tourism \\ Zaporizhzhia National University \\ Zhukovskoho str., 66, Zaporizhzhia, Ukraine \\ orcid.org/0000-0001-6201-4596 \\ handball.survey@gmail.com
}

Key words: handball, physical training, innovative means.
The purpose of the study is to analyze the use of innovative means in the educational and training process in handball. The object of the research is the educational and training process in handball. The subject matter of the research is indicators of the level of physical fitness. The subject of the research is the boys of the "Handball Academy" team. Research methods: analysis and generalization of scientific and methodological sources on the research topic; pedagogical observations; pedagogical experiment; methods of determining the level of physical fitness; methods of mathematical statistics in the processing of research results. Research results. Comparative analysis of the final data of the control (engaged in traditional methods) and experimental (using innovative means and technical means) groups found significant changes in four tests out of eight: in a triple jump, a complex exercise, throwing the ball at a distance with one hand standing and two hands sitting. Conclusions. The solution to the problem of improving the quality of handball training involves the widespread use of innovative information technologies in the system of sports training, which requires systematic improvement of training sessions, modernization of sports training methods, use of scientific and technological progress and advanced sports and pedagogical experience. The introduction of innovative and information technologies allows to optimize the process of formation, development and improvement of physical qualities of handball players. With their help not only the emotional background increases, but also training is accelerated or certain skills are improved. Such technical means will allow handball players to focus more on training and get more effective result. Thus, the proposed exercises for quantifying the speed of reaction and the level of special performance of the athlete in terms of active selection of useful information can be widely used at all stages of formation or improvement of sportsmanship, because the invention is based on bringing sports training to real game.
Вступ. Аналіз науково-методичної літератури свідчить про те, що в гандболі вивчені фізичні якості гравців [3], нормативи спеціальної та фізичної підготовки [8; 11], деякі питання техніки i тактики гри [6; 7]. Також представлені результати практичної роботи $з$ організації контролю за реалізацією планів тренування щодо вдосконалення фізичної підготовки гандболістів високої кваліфікації в різних структурних утвореннях річного циклу тренування [5].

Для розрахунку рівня теоретичних знань, тактичного мислення гандболістів і збереження результатів, для перегляду їхньої динаміки на визначеному етапі підготовки розроблена автоматизована методика діагностування. Упровадження в навчально-тренувальний процес дозволить створити для спортсменів такі умови чуттєвого відображення дійсності, завдяки яким за короткий час об'єктивно визначаються закономірності рухів під час техніко-тактичних дій, що недоступні в разі використання традиційних методів організації діяльності $[9 ; 10]$.

У спортивних іграх широко використовуються i тренажери: для навчання кидковим рухам [2]; техніки довгої передачі м'яча [12], удару нападу [1]; для оцінки спеціальних координаційних здібностей $[4 ; 8]$.

Серед досліджень у галузі фізичного виховання i спорту досить часто застосовується комп'ютерна програма експрес-оцінки рівня функціональної підготовленості організму спортсменів «ШВСМ», використання якої виявилося досить ефективним під час роботи зі спортсменами, що спеціалізуються в різних видах спорту, зокрема гандболі [14].

Мета роботи - здійснити аналіз використання інноваційних засобів у навчально-тренувальному процесі в гандболі. 
Методи дослідження. Методи теоретичного рівня дослідження: аналіз, порівняння, синтез, систематизація й узагальнення даних науково-методичної літератури та контенту мережі Інтернет, спрямовані на виявлення проблем і суперечностей, пов'язаних із навчально-тренувальним процесом у гандболі, інтеграцією новітніх наукових досягнень у систему підготовки спортсменів.

Під час теоретичного дослідження науково-методичної літератури проаналізовано дані досліджень та досвід практичної діяльності українських і зарубіжних фахівців у галузі загальної теорії і методики підготовки спортсменів, зокрема в гандболі. Аналіз і синтез були використані для конкретизації загального уявлення про особливості підготовки гандболістів. Основна увага приділялася процесу підготовки спортсменів, використанню інноваційних засобів у навчально-тренувальному процесі, методиці розвитку фізичних якостей гандболістів.

Методи емпіричного рівня дослідження: аналіз документальних матеріалів; педагогічне спостереження - проводилося для здійснення аналізу організації навчально-тренувального процесу, використання інноваційних технічних засобів під час підготовки, уточнення досліджуваної проблеми. Педагогічне спостереження було за обізнаністю відкритим, за стилем - включеним, за спрямованістю - тематичним, за програмою - основним. Педагогічний експеримент використано для перевірки впливу інтерактивних засобів підготовки на рівень фізичної підготовленості гандболістів.

Педагогічне тестування - для визначення рівня фізичної підготовленості гандболістів. Застосовувалися контрольні нормативи: біг 30 м, с; ведення м'яча 30 м, с; потрійний стрибок із місця, см; метання м'яча (масою 1 кг) на дальність стоячи однією рукою, м; метання м'яча (масою 1 кг) на дальність двома руками сидячи, м; човниковий біг 2 х 100 м, с; виходи, с; комплексна вправа, с.

Методи статистичної обробки експериментальних даних - для здійснення аналізу емпіричних даних педагогічного експерименту за допомогою комп'ютерної програми STATISTICA 10.0.

Організація дослідження. Педагогічний експеримент проведений на базі гандбольної команди «Академія гандболу» (Запоріжжя, Україна). У дослідженні взяли участь 24 гандболісти, 3 яких сформовані експериментальна i контрольна групи (по 12 осіб). Порівняння показників гандболістів проводилося два рази - на початку і в кінці дослідження.

Контрольна група займалася за традиційною методикою [3], експериментальна - з використанням інноваційних засобів (пліобокси, Bosu-платформи, мотузкові сходи, канати, ролики для преса, SandBag) та інноваційних технічних засобів - гандбольних світлових вправ (Light Handball Trainer), що являють собою простий в установці і використанні бездротовий девайс із лазерними датчиками, які передають червоне $\mathrm{i}$ зелене світло, які використовуються для активації або деактивації рухів.

Час вправи визначається тренером залежно від поставленого завдання або виховання певних фізичних якостей. Можна запрограмувати різні режими вправ, складність і тривалість. Ця функція мобільності дозволяє використовувати різноманітні вправи, ускладнювати які можна за допомогою передачі гандбольного і набивного м'ячів.

Спалах ламп відбувається за допомогою комп'ютерної програми стандартних випадкових чисел [8]. Вправи застосовувалися протягом 20-25 хвилин після розминки, в основній частині тренування. Варіація компонентів фізичних навантажень під час виконання тієї самої вправи (вид застосовуваних вправ, інтенсивність, тривалість виконання вправ, кількість повторень, час i характер відпочинку між вправами) надавала можливість змінювати спрямованість тренувальних навантажень із метою підтримки фізичної підготовленості гандболістів. Так, наприклад, у разі застосування вправ, що використовуються для розвитку стрибучості, якщо збільшити тривалість їх виконання з 15-20 с до 30-40 с і кількість серій із 4-6 до 6-8, спрямованість тренувального впливу вже має характер розвитку спеціальної (стрибкової) витривалості.

Виклад основного матеріалу дослідження. Сучасний гандбол - це динамічна й атлетична гра, яка вимагає високих рухових і функціональних можливостей спортсменів, де відбувається значне навантаження динамічної силової роботи змінної потужності. Чергування активних i пасивних фаз у його ігровій діяльності - через кожні 3-20 секунд. За матч польовий гравець, за допомогою різних способів переміщення, долає відстань у $6000-8000$ метрів, здійснює приблизно 30 стрибків, вступає в активне єдиноборство із гравцями суперника не менше 40 разів. Інтенсивність ігрової діяльності гандболістів безперервно змінюється.

Відповідно до обраної схеми аналізу експериментальних даних, для визначення правильності підбору засобів, методів, форм занять у процесі підготовки в гандбольному клубі, нами здійснено порівняльний аналіз відповідних показників протягом дослідження спортсменів контрольної й експериментальної груп (рис. 1).

Так, статистично достовірні відмінності між початком i кінцем дослідження в контрольній групі засвідчені за показниками потрійного стрибка з місця (на початку $-718,3 \pm 8,2 \mathrm{cm;} \mathrm{у}$ кінці - 737,9 $\pm 5,1$ см) і метання м'яча (масою 1 кг) 


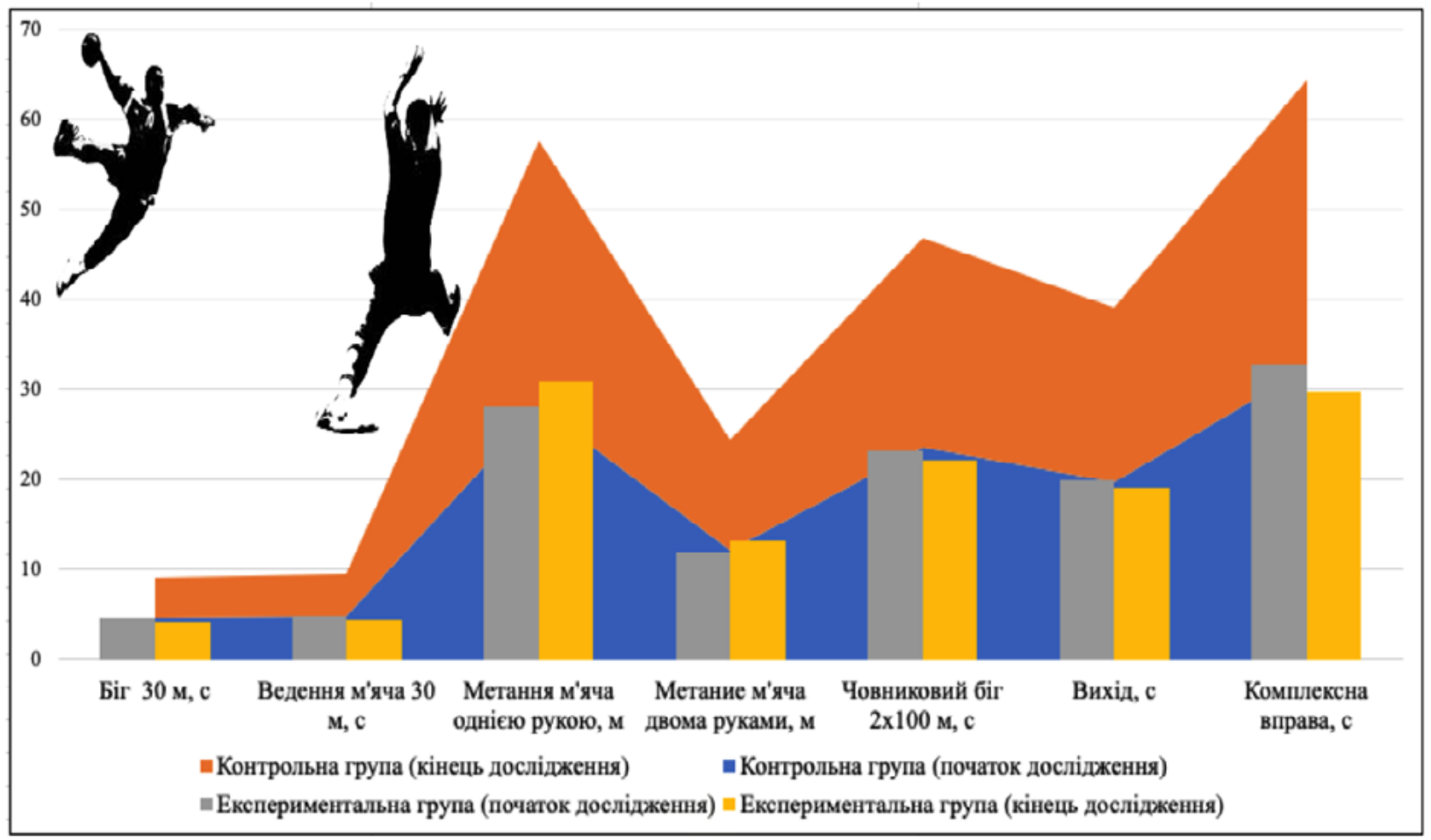

Рис. 1. Порівняльний аналіз показників гандболістів контрольної й експериментальної груп протягом дослідження

на дальність стоячи однією рукою (на початку $28,13 \pm 0,6$ м; у кінці - 29,6 \pm 0,3 м). За іншими результатами тестування зафіксована тенденція до покращення. В експериментальній групі спостерігалися зрушення, що засвідчили ефективність використання інноваційних засобів.

Застосування парного t-тесту Стьюдента показало, що різниця є статистично достовірною за результатами: потрійного стрибка 3 місця (на початку - 715,6 \pm 7,21 см; у кінці - 765,8 \pm 5,3 cм), метання м'яча (масою 1 кг) на дальність стоячи однією рукою (на початку - 28,1 $\pm 0,5$ м; у кінці $30,9 \pm 0,4$ м). Результати в метанні м'яча (масою 1 кг) на дальність двома руками сидячи також достовірно покращилися протягом дослідження (на початку $-11,9 \pm 0,3$ м; у кінці $-13,2 \pm 0,2$ м). У човниковому бігу 2 х 100 м (на початку - 23,2 \pm 0,3 c; у кінці-22,1 $\pm 0,3$ с) і комплексному тесті (на початку - 32,8 $\pm 0,5$ c; у кінці - 29, $8 \pm 0,52$ с) зафіксована статистична тенденція змін. За іншими контрольними вправами (біг 30 м, ведення м'яча 30 м, виходи) показано, що характер позитивних змін показників був суто тенденційний, з відсутністю статистично достовірних відмінностей.

Висновки. Динаміка показників розвитку фізичних якостей гандболістів обох групи протягом дослідження показала, що в контрольній групі статистично достовірні відмінності між початком і кінцем дослідження зафіксовані у двох тестах із восьми (у потрійному стрибку 3 місця і метанні м’яча (масою 1 кг) на дальність однією рукою стоячи), а в експериментальній групі - у п'яти тестах iз восьми (у потрійному стрибку з місця, метанні м'яча (масою 1 кг) на дальність однією рукою стоячи, метанні м’яча (масою 1 кг) на дальність двома руками сидячи, човниковому бігу 2 х 100 м, комплексній вправі).

Причому статистично ймовірнісний аналіз результатів тестових випробувань вказав на високу статистичну значущість отриманих показників в експериментальній групі в чотирьох із п'яти: у потрійному стрибку 3 місця, метанні м'яча (масою 1 кг) на дальність однією рукою стоячи, метанні м'яча (масою 1 кг) на дальність двома руками сидячи, комплексній вправі ( $<0,001)$.

Порівняльний аналіз прикінцевих даних контрольної й експериментальної груп констатував достовірні зміни в чотирьох тестах із восьми: у потрійному стрибку 3 місця ( $<0,01)$, метанні м'яча (масою 1 кг) на дальність однією рукою стоячи (p < 0,05), метанні м'яча (масою 1 кг) на дальність двома руками сидячи ( $<0,01)$, комплексній вправі $(\mathrm{p}<0,01)$.

Гандбольні світлові вправи (Light Handball Trainer) можуть ефективно використовуватися під час навчально-тренувального процесу для поліпшення спритності, бистрості та швидкості реакції. Такі технічні засоби дозволять гандболістам більше зосередитися на тренуванні й отримати більш дієвий результат. Отже, запро- 
поновані вправи кількісної оцінки швидкості реакції і рівня спеціальної працездатності спортсмена в умовах активного вибору корисної інформації можуть широко застосовуватися на всіх етапах формування або вдосконалення спортивної майстерності, оскільки в основу винаходу покладено наближення спортивного тренування до умов реальної гри.

Перспективи подальших пошуків можуть бути спрямовані на використання описаних інноваційних засобів для функціональних тренувань у період реабілітації спортсменів.

\section{ЛІТЕРАТУРА}

1. Артемьев О.В. Эффективность использования специальных тренажерных устройств в обучении технике нападающего удара в волейболе. Теория и методика обучения и воспитания в современном образовательном пространстве. 2018. С. 93-101.

2. Ермаков С.С. Тренажери для навчання ударним і кидковим рухам у спортивних іграх. Слобожанський науково-спортивний вісник. 1998. Вип. 1. С. 143-144.

3. Игнатьева В.Я. Гандбол. Москва : Физическая культура, 2008. 384 с.

4. Красильников В.Н., Мехдиева К.Р., Захарова А.В. Оценка специальных координационных способностей футболистов с применением светового тренажера "Fitlight". Физическая культура и cnopm: наука, образование, технологии. 2019. С. 82-84.

5. Латышкевич Л.А., Турчин И.Е., Маневич Л.Р. Гандбол. Киев : Вища школа, 1988. 198 с.

6. Мельник В.О. Удосконалення атакувальних тактичних дій гандболістів на етапі підготовки до вищих досягнень : автореф. дис. ... канд. наук з фіз. вихов. та спорту. Львів, 2015. 18 с.

7. Сердюк Д.Г. Удосконалення техніко-тактичних дій кваліфікованих гандболістів на основі контролю показників змагальної діяльності : автореф. дис. ... канд. наук 3 фіз. вихов. та спорту. Дніпро, 2016. 24 с.

8. Тищенко В.О., Черненко О.С., Сердюк Д.Г. Комп’ютерна програма для визначення координаційних здібностей в гандболі. Свідоцтво про реєстрацію авторського права на твір. Запоріжжя, 2015.

9. Тищенко В.А., Соколова О.В., Сапун Т.А. ІТ-технологии как средство определения уровня теоретической подготовки в спорте высших достижений. Вісник Запорізького національного університету. 2019. № 2. С. 108-115.

10. Фролова Л.С., Глазирін І.Д. Використання методики “Balltest” як педагогічного методу підвищення рівня розвитку ігрового і тактичного мислення гандболістів. Вісник Запорізького національного університету. 2009. № 2. С. 155-160.

11. Хомутов Н.И. Исследование нормативов по физической и специальной подготовке гандболистов высших разрядов. Киев, 1990. $80 \mathrm{c}$.

12. Чарикова Е.Н. Тренажер для обучения технике длинной передачи мяча в баскетболе способом согнутой рукой сверху с замахом. Физическое воспитание студентов. Харьков : ХГАДИ, 2012. № 3. C. 116-118.

13. Use of innovative technical means to increase the training process effectiveness in handball / V. Lochman et al. Journal of Physical Education and Sport. 2021. Vol. 21 (4). Art. 215. P. 1695-1704.

14. Modern and methodic approaches to express-assessment of functional preparation of highly qualified athletes / M. Malikov et al. Journal of Physical Education and Sport. 2019. Vol. 19 (3). Art. 219. P. 1513-1518.

15. The concept of building control for certain components of the system for training handball players / V.O. Tyshchenko et al. Journal of Physical Education and Sport. 2019. № 19 (4). Art. 200. P. 1380-1385.

\section{REFERENCES}

1. Artem'yev O.V. (2018). Effektivnost' ispol'zovaniya spetsial'nykh trenazhernykh ustroystv v obuchenii tekhnike napadayushchego udara v voleybole. Teoriya $i$ metodika obucheniya $i$ vospitaniya $v$ sovremennom obrazovatel'nom prostranstve. S. 93-101.

2. Yermakov S.S. (1998). Trenazheri dlya navchannya udarnim i kidkovim rukham v sportivnikh igrakh. Slobozhans 'kiy naukovo-sportivniy visnik. Vip. 1. S. 143-144.

3. Ignat'yeva V.Ya. (2008). Gandbol. Moskva : Fizicheskaya kul'tura. 384 s.

4. Krasil'nikov V.N., Mekhdiyeva K.R., Zakharova A.V. (2019). Otsenka spetsial'nykh koordinatsionnykh sposobnostey futbolistov s primeneniyem svetovogo trenazhera "Fitlight". Fizicheskaya kul'tura i sport: nauka, obrazovaniye, tekhnologii. S. 82-84.

5. Latyshkevich L.A., Turchin I.Ye., Manevich L.R. (1988). Gandbol. Kiyev : Vishcha shkola, 1988.198 s.

6. Mel'nyk V.O. (2015). Udoskonalennya atakuval'nykh taktychnykh diy handbolistiv na etapi pidhotovky do vyshchykh dosyahnen' : avtoref. dys. ... kand. nauk z fiz. vykhovannya ta sportu, L'viv. 18 c. 
7. Serdyuk D.H. (2016). Udoskonalennya tekhniko-taktychnykh diy kvalifikovanykh handbolistiv na osnovi kontrolyu pokaznykiv zmahal'noyi diyal'nosti : avtoref. dys. ... kand. nauk z fiz. vykhovannya ta sportu, Dnipro. $24 \mathrm{~s}$.

8. Tyshchenko V.O., Chernenko O.Ye., Serdyuk D.H. (2015). Komp'yuterna prohrama dlya vyznachennya koordynatsiynykh zdibnostey $\mathrm{v}$ handboli. Svidotstvo pro reyestratsiyu avtors'koho prava na tvir. Zaporizhzhya.

9. Tyshchenko V., Sokolova O., Sapun T. (2019). IT-tekhnolohyy kak sredstvo opredelenyya urovnya teoretycheskoy podhotovky v sporte vysshykh dostyzhenyy. Visnyk Zaporiz'koho natsional'noho universytetu, Zaporizhzhya: Zaporiz'kyy natsional'nyy universytet. № 2. S. 108-115.

10. Frolova L.S., Hlazyrin, I.D. (2009). Vykorystannya metodyky "Balltest" yak pedahohichnoho metodu pidvyshchennya rivnya rozytku ihrovoho i taktychnoho myslennya handbolistiv. Visnyk Zaporiz'koho natsional'noho universytetu, Zaporizhzhya : Zaporiz'kyy natsional'nyy universytet. № 2. S. 155-160.

11. Khomutov N.I. (1990). Issledovaniye normativov po fizicheskoy i spetsial'noy podgotovke gandbolistov vysshikh razryadov, Kiyev. $80 \mathrm{~s}$.

12. Charykova Ye.N. (2012). Trenazher dlya obucheniya tekhnike dlinnoy peredachi myacha v basketbole sposobom sognutoy rukoy sverkhu s pokusheniyem. Fizicheskoye vospitaniye studentov. KHGADI. № 3. S. $116-118$.

13. Lochman V., Tyshchenko V., Tovstopiatko F., Pyptiuk P., Ivanenko S., Pozmogova N. (2021). Use of innovative technical means to increase the training process effectiveness in handball. Journal of Physical Education and Sport ${ }^{\circledR}(J P E S)$, Vol. 21 (4), Art. 215, pp. 1695-1704.

14. Malikov M., Tyshchenko V., Boichenko K., Bogdanovska N., Savchenko V., Moskalenko N. (2019). Modern and methodic approaches to express-assessment of functional preparation of highly qualified athletes. Journal of Physical Education and Sport (JPES), Vol. 19 (3), Art. 219, pp. 1513-1518.

15. Tyshchenko V., Lisenchuk G., Odynets T., Cherednichenko I., Lytvynenko O., Boretska N., Semeryak Z. (2019). The concept of building control for certain components of the system for training handball players. Journal of Physical Education and Sport, 19 (4), Art. 200, pp. 1380-1385. 